\title{
Influence of $\mathrm{CeAlO}_{3}$ nanoparticles on the performances of silane coatings for AZ31 alloy
}

\author{
F. Zanotto,* A. Frignani, A. Balbo, V. Grassi and C. Monticelli \\ Corrosion and Metallurgy Study Centre "A. Daccò”, Dept. Engineering, University of \\ Ferrara, Via G. Saragat 4a, 44122 Ferrara, Italy \\ *E-mail: zntfrc@unife.it
}

\begin{abstract}
This research investigates the influence exerted by $\mathrm{CeAlO}_{3}$ nanoparticle additions on the protective performances of some silanes (3-mercapto-propyl-trimethoxy-silane, PSH; vinyltrimethoxy-silane, VS; 3-(trimethoxysilyl)propyl-methacrylate, PSMA; 1,2-bis(triethoxysilyl)-ethane, BTSE), used as conversion coatings for AZ31 Mg alloy. Among the tested silanes, PSH is the most efficient one, followed by the vinyl derivatives (VS and PSMA) and finally by BTSE. In fact, in comparison to the other silanes, PSH determines a more significant reduction in the cathodic and anodic polarization currents and maintains a higher degree of protection for at least $24 \mathrm{~h}$. Afterwards, it gradually loses its protective effects. Conversely, VS, BTSE, PSMA conversion coatings allow the onset of significant corrosion rates within a few hours. In all silane coatings, the addition of $\mathrm{CeAlO}_{3}$ nanoparticles increases both the coating protectiveness and the persistence of the protective action. In particular, the higher the silane coating performance, the greater the enhancing effect of the nanoparticles. Thus, $\mathrm{CeAlO}_{3}$ nanoparticles particularly improve the protectiveness of PSH conversion coating, which displays an inhibiting efficiency of over $99 \%$, after $168 \mathrm{~h}$ of immersion in $0.1 \mathrm{M} \mathrm{NaCl}$ solution. On this coating type containing nanoparticles, the electrochemical impedance spectra (EIS) and the scanning electron microscopy (SEM) observations evidence an increase in the layer thickness from $3.5 \pm 0.5 \mu \mathrm{m}$ to $5.6 \pm 0.6 \mu \mathrm{m}$ and a decrease in the layer porosity. Therefore, the nanoparticles induce slower diffusion processes, which particularly slow down the anodic reaction, so hindering the overall corrosion process.
\end{abstract}

Keywords: magnesium, conversion coating, nanoparticles, silane, EIS, SEM.

Received: July 31, 2019. Published: November 12, 2019

doi: $\underline{10.17675 / 2305-6894-2019-8-4-10}$

\section{Introduction}

The conventional corrosion protection methods for $\mathrm{Mg}$ alloys involve the preventive application of conversion coatings based on chromates, which are currently not acceptable due to their toxicity towards humans and environment [1]. Therefore, many efforts were performed to identify non hazardous protection methods, ranging from corrosion inhibitor 
applications [2-5], to surface conversion coatings based on carboxylates [6,7], stannates and permanganates [8-10] or different silane types [11-15].

The protective performance of a silane layer mainly depends on the barrier properties exerted towards the penetration of the aggressive solutions: therefore, an increase in the thickness of the layer as well as a diminution in its porosity (chiefly interconnected) can enhance its performances. Nanoparticle addition may actually improve the coating efficiency by increasing the coating thickness and partially obstructing its porosity, as well as by increasing the silane reticulation degree. For instance, nanoparticles like silica $\left(\mathrm{SiO}_{2}\right)$, ceria $\left(\mathrm{CeO}_{2}\right)$, zirconia $\left(\mathrm{ZrO}_{2}\right)$ or ceria.zirconia $\left(\mathrm{CeO}_{2} \cdot \mathrm{ZrO}_{2}\right)$ were tested as silane bath additives for the corrosion protection of galvanized steel [16-21], carbon steel [22-24] and aluminum alloy [25-31] substrates. Palanivel et al. [25] demonstrated that a small addition of silica nanoparticles to a bis-sulfur silane (bis-[triethoxysilyl-propyl]tetrasulfide, BTESPT) bath mitigated aluminium alloy corrosion by slowing down the alloy cathodic reaction. These nanoparticles also increased the silane film thickness and improved the film mechanical strength. However, it was observed that the protective performances depended on the amount of silica, as a too large amount caused a quicker water uptake through the film pores, leading to its premature deterioration. Other authors confirmed the enhancement in corrosion protection of silane films on galvanized (BTESPT and bis-1,2[triethoxysilyl]-ethane, BTSE) [17] or carbon steel (bis-[trimethoxysilylpropylamine], BTSPA) [22] substrates, when loaded by silica micro- or nanoparticles, due to an increase in the barrier effect and coating thickness. On the other side, these particles were not able to impede corrosion activity in artificial defects created in the silane coatings [18]. Better performances were achieved by $\mathrm{CeO}_{2}$ addition, which not only improved the barrier effect of the BTESPT coating, but also provided inhibition ability in scratched surfaces $[16,18]$. Even $\mathrm{ZrO}_{2}$ nanoparticles increased the silane coating protectiveness by lowering the film defectiveness, likely due to a pore blocking effect [27]. Zheludkevich et al. [26] showed that $\mathrm{ZrO}_{2}$ nanostructured silane film was able to remain highly protective for a limited period, due to the formation of cracks, allowing the electrolyte access to the aluminium substrate. On the other hand, the same authors observed a higher ability of $\mathrm{CeO}_{2} \cdot \mathrm{ZrO}_{2}$ nanoparticles to delay the corrosion activity at film defects thanks to the $\mathrm{CeO}_{2}$ component, rather than to the $\mathrm{ZrO}_{2}$ one [19].

Even if silane conversion coatings have been widely tested for $\mathrm{Mg}$ alloy corrosion protection, researches on the influence of nanoparticle charging in silane coatings are still rather limited [31-33]. In our lab, on AZ31 Mg alloy various nano-powders (titania, zirconia, ceria, ceria-zirconia) were tested as means for improving the performances of 3-mercapto-propyl-trimetoxysilane (PSH) coatings [34]. It was found that the enhancing effects were independent from the size of the nanoparticles, while instead they depended on the particular oxide type, being $\mathrm{CeO}_{2}$ and $\mathrm{CeO}_{2} \cdot \mathrm{ZrO}_{2}$ the most efficient ones.

The present research investigates the influence of cerium aluminate nanoparticles $\left(\mathrm{CeAlO}_{3}\right)$ on the protective features of various silanes: 3-mercaptopropyl-trimethoxysilane 
(PSH), 1,2-bis-triethoxysilyl-ethane (BTSE), vinyltrimethoxysilane (VS) and 3-trimethoxysilyl-propyl-methacrylate (PSMA). As conversion coatings, PSH [11, 13, 35], BTSE [36-38] and TEOS-PSMA [31] were already tested on Mg alloys, while VS was investigated as $\mathrm{Al}$ alloy coating [39,40]. However, a parent compound of VS (i.e. vinyltriethoxysilane) was applied with positive effects on AZ91D Mg alloy in hybrid coatings $[41,42]$. VS and PSMA can enhance the coating cross-linking not only by the polysiloxane bond, but also through the carbon-carbon $(-\mathrm{C}=\mathrm{C}-)$ double bond reticulation $[43,44]$. Nevertheless, all these silane layers were characterized by a certain porosity, which determined a more or less rapid gradual decrease in their efficiency.

\section{Experimental}

Square electrodes $(1 \mathrm{~cm} \times 1 \mathrm{~cm})$ of AZ31 magnesium alloy (nominal composition by weight: Al, 2.5-3.5\%; $\mathrm{Zn}, 0.7-1.3 \% ; \mathrm{Mn}, 0.2-1.0 \%$; $\mathrm{Si}<0.05 \% ; \mathrm{Cu}<0.01 \%$; $\mathrm{Fe}<0.002 \%$; $\mathrm{Ni}<0.001 \%)$ were embedded in epoxy. Their surfaces were prepared by grinding with emery papers up to 1000 grade, washed with deionized water, degreased with acetone and dried with hot air. These specimens were initially pretreated in $10 \% \mathrm{HF}$ solution for $60 \mathrm{~s}$, then they were hot air dried and immersed for $30 \mathrm{~s}$ in the silane baths, regulated at $\mathrm{pH} 4$ by addition of some drops of diluted $\mathrm{H}_{2} \mathrm{SO}_{4}$ solution. After drying under a hot air flux, they were finally cured for $1 \mathrm{~h}$ at $100^{\circ} \mathrm{C}$. The silanes used in the treatment baths (90/5/5 v/v/v ethyl alcohol/water/silane solutions) were: 3-mercaptopropyltrimethoxysilane ( $\left.\mathrm{HS}-\left(\mathrm{CH}_{2}\right)_{3}-\mathrm{Si}\left(\mathrm{OCH}_{3}\right)_{3}, \mathrm{PSH}\right) ; 1$,2-bis(triethoxysilyl)ethane $\left(\left(\mathrm{OCH}_{3}\right)_{3} \mathrm{Si}-\right.$ $\left(\mathrm{CH}_{2}\right)_{2}-\mathrm{Si}\left(\mathrm{OCH}_{3}\right)_{3}$, BTSE); vinyltrimethoxysilane $\left(\mathrm{CH}_{2}=\mathrm{CH}-\mathrm{Si}\left(\mathrm{OCH}_{3}\right)_{3}, \quad \mathrm{VS}\right)$ and 3-trimethoxysilylpropyl methacrylate $\left(\mathrm{CH}_{3}-\mathrm{C}\left(=\mathrm{CH}_{2}\right)-\mathrm{COO}-\left(\mathrm{CH}_{2}\right)_{3}-\mathrm{Si}\left(\mathrm{OCH}_{3}\right)_{3}\right.$, PSMA) (all Aldrich products).

In order to achieve reproducible results, the silane baths were maintained under stirring for $12 \mathrm{~h}$ and utilized after $24-48 \mathrm{~h}$ hydrolysis time. In the case of nanoparticlecharged coatings, $250 \mathrm{ppm} \mathrm{CeAlO}_{3}$ (cerium aluminate) nanoparticles (<50 nm [BET], Aldrich product) were added to the hydrolyzed silane solution.

Electrochemical tests were performed with a Princeton Applied Research PARSTAT2263 Potentiostat-Galvanostat, in a $25( \pm 1)^{\circ} \mathrm{C}$ thermostated $250 \mathrm{ml}$ glass cell with a 3-electrode assembly: a working electrode, a reference electrode (saturated calomel electrode, SCE) and two symmetrical platinum wire counter-electrodes. The aggressive solution was $0.1 \mathrm{M} \mathrm{NaCl}$ (Carlo Erba RPE product).

The potentiodynamic polarization curves were recorded by applying a $0.2 \mathrm{mV} \cdot \mathrm{s}^{-1}$ scanning rate, starting from the corrosion potential $\left(E_{\mathrm{CORR}}\right)$. The corrosion current $\left(i_{\mathrm{CORR}}\right)$ value was obtained by cathodic Tafel line extrapolation to $E_{\mathrm{CORR}}$, while the inhibition efficiency (\%I.E.) was calculated as:

$$
\% I . E .=\frac{i_{\mathrm{CORR}(\mathrm{BLANK})}-i_{\mathrm{CORR}(\mathrm{INHIB} .)}}{i_{\mathrm{CORR}(\mathrm{BLANK})}} \times 100
$$


The electrochemical impedance spectra (EIS) were performed at $E_{\mathrm{CORR}}$ by applying a $10 \mathrm{mV}$ (rms) sinusoidal perturbation, in the frequency range $10^{5}-10^{-3} \mathrm{~Hz}$. From these spectra, the polarization resistance values $\left(R_{\mathrm{p}}\right.$, inversely proportional to $\left.i_{\mathrm{CORR}}\right)$ were calculated, as the intercept of the low frequency capacitive loops with the real axis. Some impedance spectra were processed by Z-SimpWin software, to obtain the parameter values of the best fitting Electrical Equivalent Circuit (EEC) [45].

The thickness of the most efficient silane layers was evaluated by embedding in epoxy two coated samples with the silane layers in close contact to each other. The double sample so achieved was cut perpendicularly to the silane layers and the obtained sections were ground by emery paper and then polished by diamond colloidal suspension down to $1 \mu \mathrm{m}$ roughness. Finally, the average layer thickness was measured as the half of whole silane thickness, by observations with a scanning electron microscope (SEM) equipped by energy dispersive X-ray spectroscopy (EDS).

\section{Results}

Figure 1 shows the polarization curves recorded on AZ31 Mg alloy treated by PSH, in the absence and presence of $\mathrm{CeAlO}_{3}$ nanoparticles. As a reference, the polarization curves of the bare alloy are also reported. At short testing times (Figure 1a), PSH efficiently protected AZ31 alloy from corrosion, chiefly by hindering the cathodic hydrogen evolution reaction, as shown by the decrease of about two orders of magnitude in the cathodic polarization currents. Consequently, the corrosion potential $\left(E_{\mathrm{CORR}}\right)$ shifted in the negative direction of about $125 \mathrm{mV}$ (Table 1). The anodic polarization curve displayed a very high slope, with a breaking potential $\left(E_{\mathrm{BR}}\right)$ of about $60 \mathrm{mV}$ more positive than that of the unprotected alloy. At increasing immersion times, the polarization curves shifted towards higher current density values, indicating a progressive decrease in PSH performances. The protective effects almost completely disappeared after $168 \mathrm{~h}$ testing (Figure 1b).
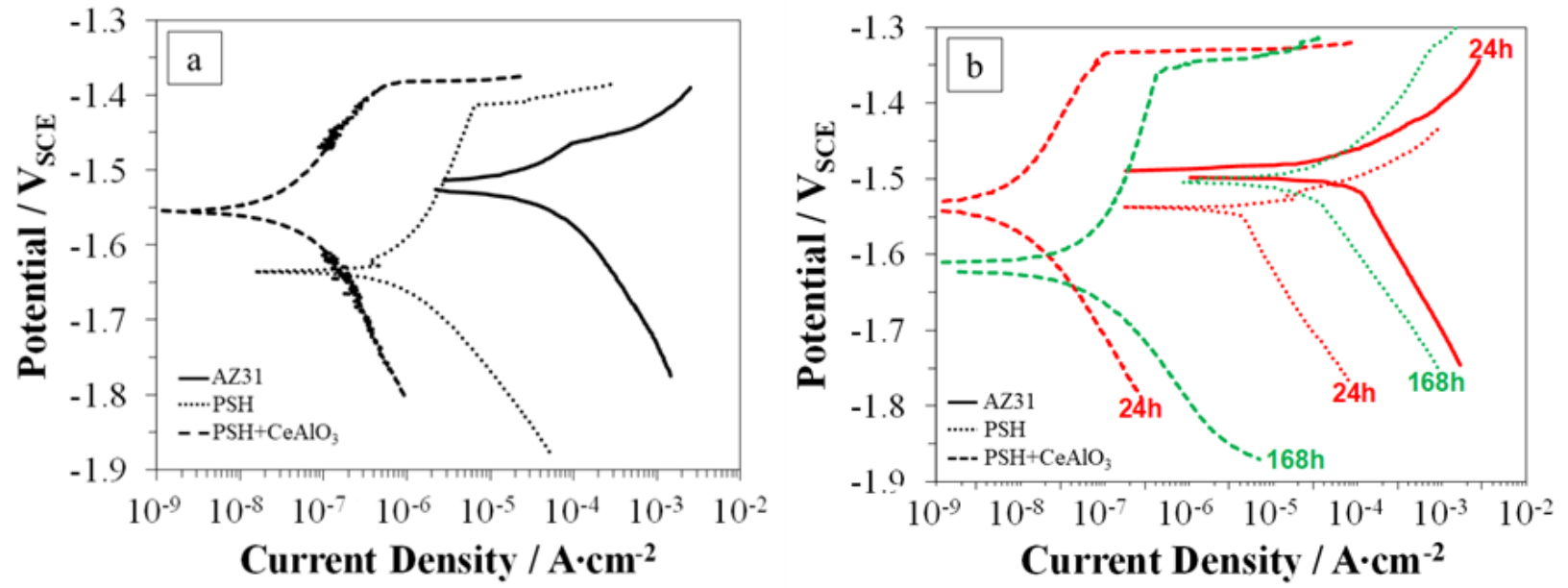

Figure 1. Polarization curves recorded on AZ31 and on PSH treated AZ31 electrodes, in the absence and presence of $\mathrm{CeAlO}_{3}$ nanoparticles, after $1 \mathrm{~h}$ (a) or 24 and 168 hours (b) of immersion in $0.1 \mathrm{M} \mathrm{NaCl}$. 
$\mathrm{CeAlO}_{3}$ nanoparticles noticeably strengthened the protective action of PSH. After $1 \mathrm{~h}$ immersion, they particularly retarded the anodic reaction (Figure 1a), with anodic currents lower than $0.1 \mu \mathrm{A} / \mathrm{cm}^{2}$ up to $-1.36 \mathrm{~V}_{\mathrm{SCE}}$. Therefore, $E_{\mathrm{CORR}}$ shifted to more positive values (Table 1) and a slight $E_{\mathrm{BR}}$ ennobling with respect to plain PSH was detected. This positive influence lasted for a very long time period (Figure 1b). After $24 \mathrm{~h}$, both the anodic and cathodic polarization currents shifted towards lower values in comparison to those recorded after $1 \mathrm{~h}$. After $168 \mathrm{~h}$, although a moderate increase in the cathodic and, particularly, the anodic currents was observed, $\mathrm{CeAlO}_{3}$-loaded PSH coating still presented cathodic currents of about three orders of magnitude lower than those of the unprotected alloy, an anodic polarization curve with currents lower than $1 \mu \mathrm{A} / \mathrm{cm}^{2}$ in a wide potential range and a $E_{\mathrm{BR}}$ value nobler than $-1.4 \mathrm{~V}_{\mathrm{SCE}}$.

Table 1. $E_{\mathrm{CORR}}$ and $E_{\mathrm{BR}}$ values after $1 \mathrm{~h}$ immersion in $0.1 \mathrm{M} \mathrm{NaCl}$ for $\mathrm{AZ} 31$ electrodes treated in the various silane baths with or without $\mathrm{CeAlO}_{3}$ nanoparticles addition.

\begin{tabular}{ccccc}
\hline \multirow{2}{*}{ Silanes } & \multicolumn{2}{c}{ Without nanoparticles } & \multicolumn{2}{c}{ With nanoparticles } \\
\cline { 2 - 5 } & $\boldsymbol{E}_{\mathbf{C O R R}}(\mathbf{m V} / \mathbf{S C E})$ & $\boldsymbol{E}_{\mathbf{B R}}(\mathbf{m V} / \mathbf{S C E})$ & $\boldsymbol{E}_{\mathbf{C O R R}}(\mathbf{m V} / \mathbf{S C E})$ & $\boldsymbol{E}_{\mathbf{B R}}(\mathbf{m V} / \mathbf{S C E})$ \\
\hline Blank & -1.525 & - & -1.525 & - \\
\hline \multirow{2}{*}{ PSH } & -1.651 & -1.415 & -1.556 & $-1.384(1 \mathrm{~h})$ \\
& -1.597 & - & -1.567 & - \\
\hline VS & -1.570 & - & -1556 & - \\
\hline PSMA & -1.592 & - & -1.574 & - \\
\hline BTSE & & - & & - \\
\hline
\end{tabular}

The conversion coating of BTSE succeeded in reducing the cathodic polarization currents only by one order of magnitude (Figure $2 \mathrm{a}$ ) and consequently after $1 \mathrm{~h}$ immersion the shift of $E_{\mathrm{CORR}}$ in the negative direction was lower than that induced by PSH (Table 1). BTSE coating presented a slightly inhibited anodic curve, characterized by a high slope in a narrow potential range and a $E_{\mathrm{BR}}$ value close to that of the blank. After $24 \mathrm{~h}$, the protective effects towards the anodic reaction increased, whereas those in the cathodic one slightly decreased (Figure 2b). The addition of nanoparticles in the coating nearly halved the anodic and cathodic currents in the polarization curves after $1 \mathrm{~h}$ immersion, but this influence was negligible after $24 \mathrm{~h}$, even if a small $E_{\mathrm{BR}}$ ennobling was ensured.

The conversion coatings of the silanes bearing a $\mathrm{C}=\mathrm{C}$ double bond (PSMA and VS, Figure 3) were more efficient than BTSE; at the beginning, these coatings noticeably reduced the cathodic polarization currents, but slightly less than PSH (Figure 1). Even their influence on the anodic reaction was lower than that of PSH (in the sequence $\mathrm{PSH}>\mathrm{PSMA}>\mathrm{VS}=\mathrm{BTSE}$ ) and their $E_{\mathrm{BR}}$ values were close to that of the unprotected specimen. These coatings, especially VS, lost their efficiency already after $24 \mathrm{~h}$ immersion: 
they maintained a fair barrier effect against the reduction process, but the hindrance they exerted towards the anodic process was negligible.
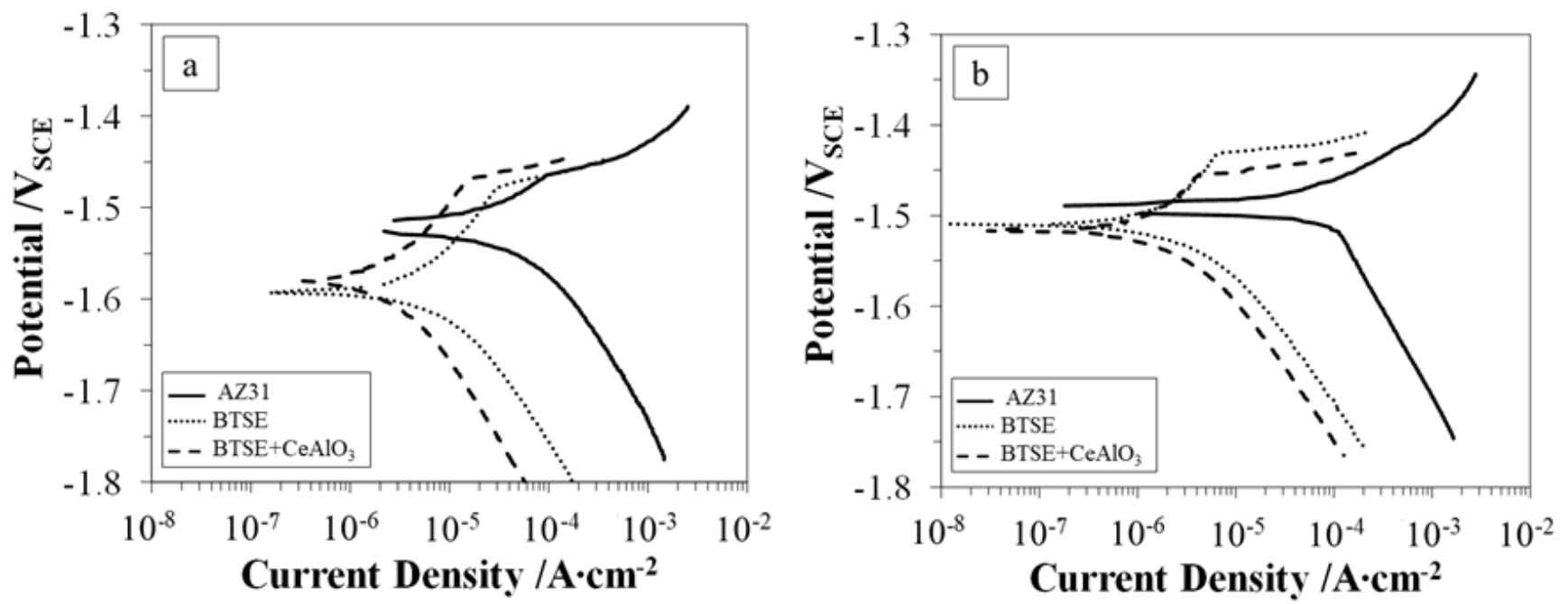

Figure 2. Polarization curves recorded on AZ31 and on BTSE treated AZ31 electrodes, in the absence and presence of $\mathrm{CeAlO}_{3}$ nanoparticles, after 1 (a) and $24 \mathrm{~h} \mathrm{(b)} \mathrm{immersion} \mathrm{in} 0.1 \mathrm{M}$ $\mathrm{NaCl}$.

The effect of $\mathrm{CeAlO}_{3}$ nanoparticles addition on these silanes was to improve the inhibiting action exerted on the anodic process (more evident in the case of PSMA), which, however, completely disappeared after $24 \mathrm{~h}$ immersion. After this time interval, only the cathodic polarization curve of $\mathrm{CeAlO}_{3}$ loaded PSMA was found to be rather more inhibited than that of the unloaded silane.

Table 2 collects the corrosion currents $\left(i_{\mathrm{CORR}}\right)$ determined by the extrapolation of the cathodic polarization curves at $E_{\mathrm{CORR}}$ for the various silane conversion coatings, in the absence and presence of nanoparticles, after 1 and $24 \mathrm{~h}$ immersions in the aggressive solution. These data allow a quantitative evaluation of the positive effect exerted by the nanoparticle addition. After $1 \mathrm{~h}$ immersion, the most efficient coating (without nanoparticles) was PSH (97.4 \%I.E.), while the least efficient was BTSE (81.8 \%I.E.). With the exception of BTSE, the $i_{\mathrm{CORR}}$ values of the silane-treated electrodes tended to increase with time: they doubled in the case of PSH, while a four time or twenty time increase was recorded in the case of PSMA or VS, respectively. Therefore, after $24 \mathrm{~h}$, the $\%$ I.E. of PSH, PSMA and VS decreased to 95.8, 66.9 and $90.3 \%$, respectively. In the case of BTSE, these values raised from 81.8 to 92.9. In the presence of $\mathrm{CeAlO}_{3}$, the $i_{\mathrm{CORR}}$ values always decreased suggesting improved performances. Quite high \%I.E. were achieved after $1 \mathrm{~h}$ immersion for all types of conversion coatings which still increased after $24 \mathrm{~h}$ in the case of loaded PSH and PSMA, to reach almost $100 \%$ and $98.6 \%$, respectively. Unfortunately, in VS the nanoparticles addition induced a marked \%I.E. decrease (from 97.9 to $76.9 \%$ ), while in BTSE the efficiency remained more or less equal. 

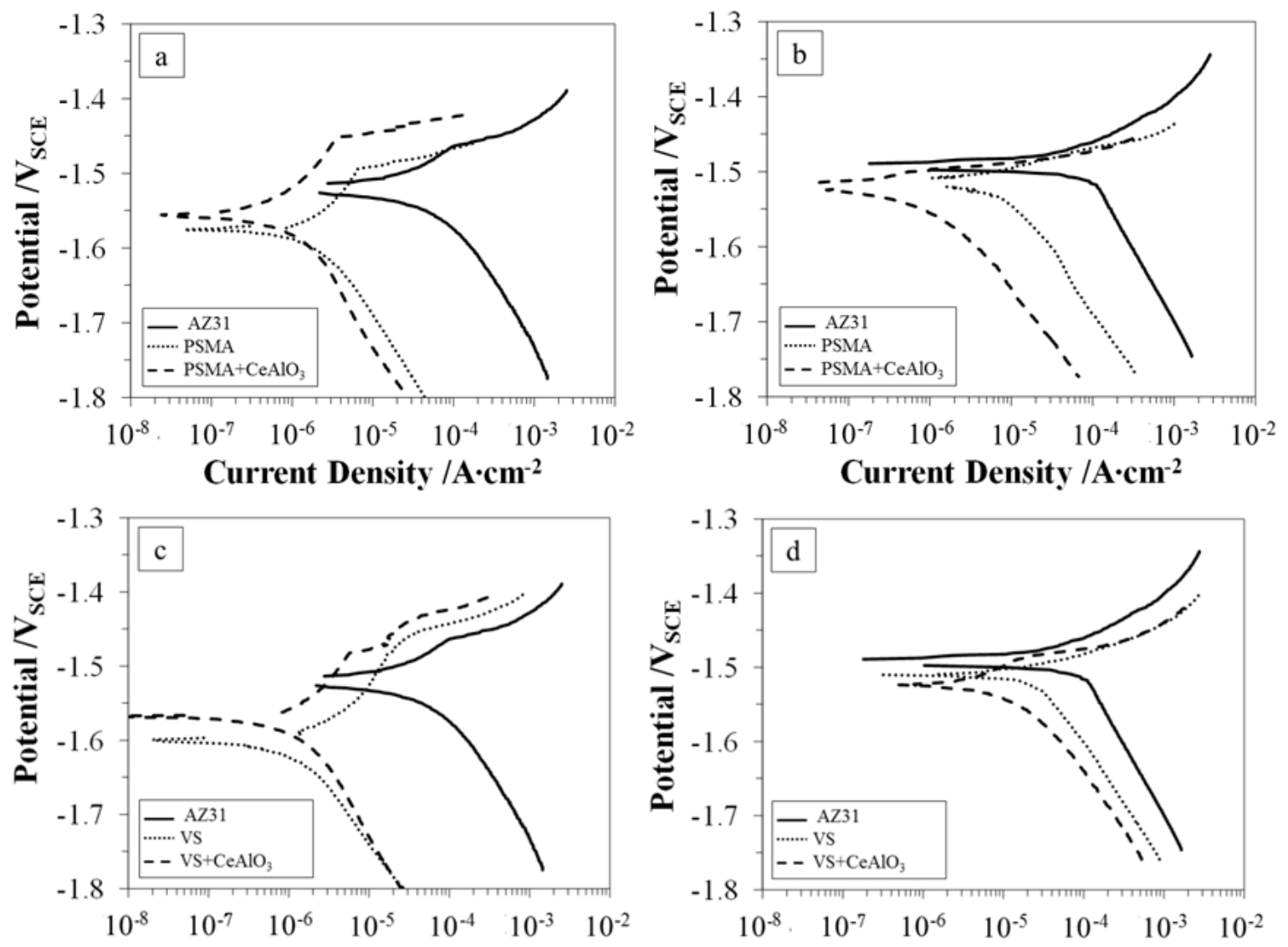

Current Density $/ \mathbf{A} \cdot \mathrm{cm}^{-2}$

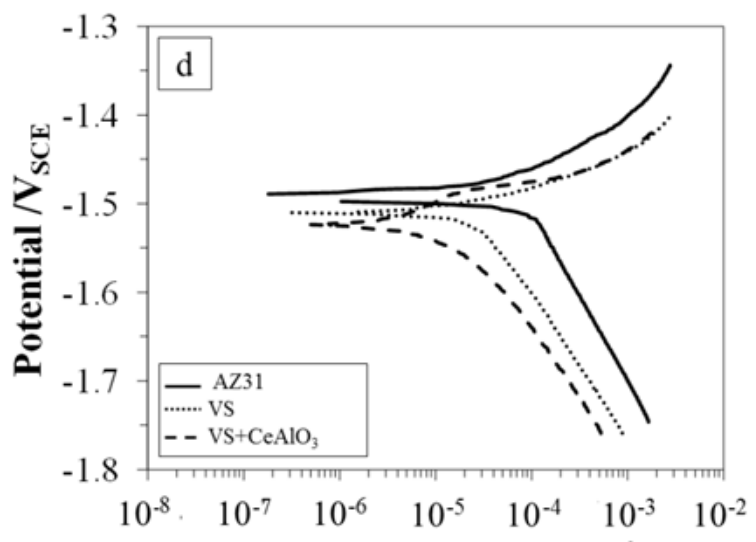

Current Density $/ \mathrm{A} \cdot \mathrm{cm}^{-2}$

Figure 3. Polarization curves recorded on AZ31 and on PSMA (a and b) or VS (c and d) treated AZ31 electrodes, in the absence and presence of $\mathrm{CeAlO}_{3}$ nanoparticles, after 1 (a and c) and $24 \mathrm{~h}$ (b and d) immersion in $0.1 \mathrm{M} \mathrm{NaCl}$.

Table 2. $i_{\text {CORR }}$ and \%I.E. values, after 1 and $24 \mathrm{~h}$ immersion in $0.1 \mathrm{M} \mathrm{NaCl}$ solution, for silane treated AZ31 electrodes, in the absence and presence of $\mathrm{CeAlO}_{3}$ nanoparticles.

\begin{tabular}{|c|c|c|c|c|c|c|c|c|}
\hline \multirow{3}{*}{ Silanes } & \multicolumn{4}{|c|}{ After $1 \mathrm{~h}$ in $0.1 \mathrm{M} \mathrm{NaCl}$} & \multicolumn{4}{|c|}{ After $24 \mathrm{~h}$ in $0.1 \mathrm{M} \mathrm{NaCl}$} \\
\hline & \multicolumn{2}{|c|}{$\begin{array}{c}\text { Without } \\
\text { nanoparticles }\end{array}$} & \multicolumn{2}{|c|}{ With nanoparticles } & \multicolumn{2}{|c|}{$\begin{array}{c}\text { Without } \\
\text { nanoparticles }\end{array}$} & \multicolumn{2}{|c|}{ With nanoparticles } \\
\hline & $\begin{array}{c}i_{\mathrm{CORR}} \\
\mu \mathrm{A} / \mathrm{cm}^{2}\end{array}$ & $\% I . E$. & $\begin{array}{c}i_{\mathrm{CORR}} \\
\mu \mathrm{A} / \mathrm{cm}^{2}\end{array}$ & $\% I . E$. & $\begin{array}{c}i_{\mathrm{CORR}} \\
\mu \mathrm{A} / \mathrm{cm}^{2}\end{array}$ & $\% I . E$. & $\begin{array}{c}i_{\mathrm{CORR}} \\
\mu \mathrm{A} / \mathrm{cm}^{2}\end{array}$ & $\%$ I.E. \\
\hline Blank & 57 & - & - & - & 86 & - & - & - \\
\hline PSH & 1.48 & $97.4 \%$ & 0.08 & $99.9 \%$ & 3.65 & $95.8 \%$ & 0.012 & $99.99 \%$ \\
\hline VS & 1.32 & $97.7 \%$ & 1.21 & $97.9 \%$ & 28.5 & $66.9 \%$ & 19.9 & $76.9 \%$ \\
\hline PSMA & 2.08 & $96.4 \%$ & 1.08 & $98.1 \%$ & 8.31 & $90.3 \%$ & 1.20 & $98.6 \%$ \\
\hline BTSE & 10.4 & $81.8 \%$ & 2.99 & $94.8 \%$ & 6.1 & $92.9 \%$ & 5.1 & $94.1 \%$ \\
\hline
\end{tabular}


As already reported for magnesium and magnesium alloys [7,46], EIS spectra (Nyquist format) of AZ31 were constituted by two more or less well-defined, capacitive semicircles and sometimes by an inductive loop. The high frequency, $h f$, capacitive arc (at frequencies around $10^{2} \mathrm{~Hz}$ ) was attributed to the charge transfer process and the corrosion products layer formation, while the other low frequency, $l f$, arc (around $10^{-1} \mathrm{~Hz}$ ) was ascribed to diffusion through this layer (Figure 4).

In comparison to the spectra of the metal substrate, those obtained on PSH conversion coating after $1 \mathrm{~h}$ immersion (Figure 4 ) were characterized by uniformly enlarged capacitive semicircles with the low frequency $(l f)$ one at the same frequency of the unprotected specimen, while the high frequency $(h f)$ one was shifted to $10^{3} \mathrm{~Hz}$. At longer immersion times, with the decrease in the coating efficiency, the former $\tau$ tended to disappear (Figure 4a, b, $168 \mathrm{~h}$ ), while the latter one moved to lower values than those in the blank. The coating decay was accompanied by the formation of a large inductive loop at very low frequencies (lower than $1 \mathrm{~Hz}$ ), which was indicative of the beginning of a strong corrosion attack.

Since the beginning of the immersion, $\mathrm{CeAlO}_{3}$ nanoparticle addition in $\mathrm{PSH}$ induced an increase in the size of the capacitive semicircles, mainly the lf one (Figure 4c, d). At short immersion times, the If $\tau$ remained at $10^{-1} \mathrm{~Hz}$, while the $h f$ one shifted to $10^{4} \mathrm{~Hz}$ (then remained constant throughout the test). Over time, the lf loop size increased up to $24 \mathrm{~h}$. Afterwards, the sizes of both $h f$ and $l f$ semicircle decreased, but the presence of the nanoparticles markedly slowed down the decay process of this coating type.

In Figure 5, the time evolution of $R_{\mathrm{p}}$ values obtained from EIS spectra in the absence and in the presence of PSH coatings is presented. Until $48 \mathrm{~h}$, the $R_{\mathrm{p}}$ of PSH treated electrodes was still appreciably higher than that of the unprotected alloy, but at the end of the test its value was close to that of the blank. $\mathrm{CeAlO}_{3}$ addition markedly slowed down the decay process of this coating: after $168 \mathrm{~h}$ immersion, $R_{\mathrm{p}}$ value was close to $580 \mathrm{k} \Omega \cdot \mathrm{cm}^{2}$ (still more than two orders of magnitude higher than that of the unloaded coating).

EIS spectra of BTSE coating presented the same shape and time constants of bare AZ31 Mg alloy (Figure 6), but with larger capacitive semicircles. This coating was less efficient than the PSH one, but its action resulted almost constant during the $24 \mathrm{~h}$ immersion time. In this case, the presence of $\mathrm{CeAlO}_{3}$ nanoparticles improved the protective effects for only a few hours (Figure 6).

The EIS spectra of PSMA (Figure 7) and VS (Figure 8) coatings were characterized by the presence of the If $\tau$ at the usual value of $10^{-1} \mathrm{~Hz}$, then two other capacitive semicircles were detected: at $10^{1} \mathrm{~Hz}$ and at $10^{3}-10^{4} \mathrm{~Hz}$. Although after $1 \mathrm{~h}$ immersion, the $R_{\mathrm{p}}$ value of PSMA was rather high (close to $30 \mathrm{k} \Omega \cdot \mathrm{cm}^{2}$ ), the performance of this coating decayed very quickly and after $24 \mathrm{~h} R_{\mathrm{p}}$ was around $4.4 \mathrm{k} \Omega \cdot \mathrm{cm}^{2}$ (Figure 9). Similarly, the initial $R_{\mathrm{p}}$ value of VS was around $55 \mathrm{k} \Omega \cdot \mathrm{cm}^{2}$, but over time the lf loop diminished its dimension and $R_{\mathrm{p}}$ values of $1.5 \mathrm{k} \Omega \cdot \mathrm{cm}^{2}$ were recorded after $24 \mathrm{~h}$ (Figure 9). 

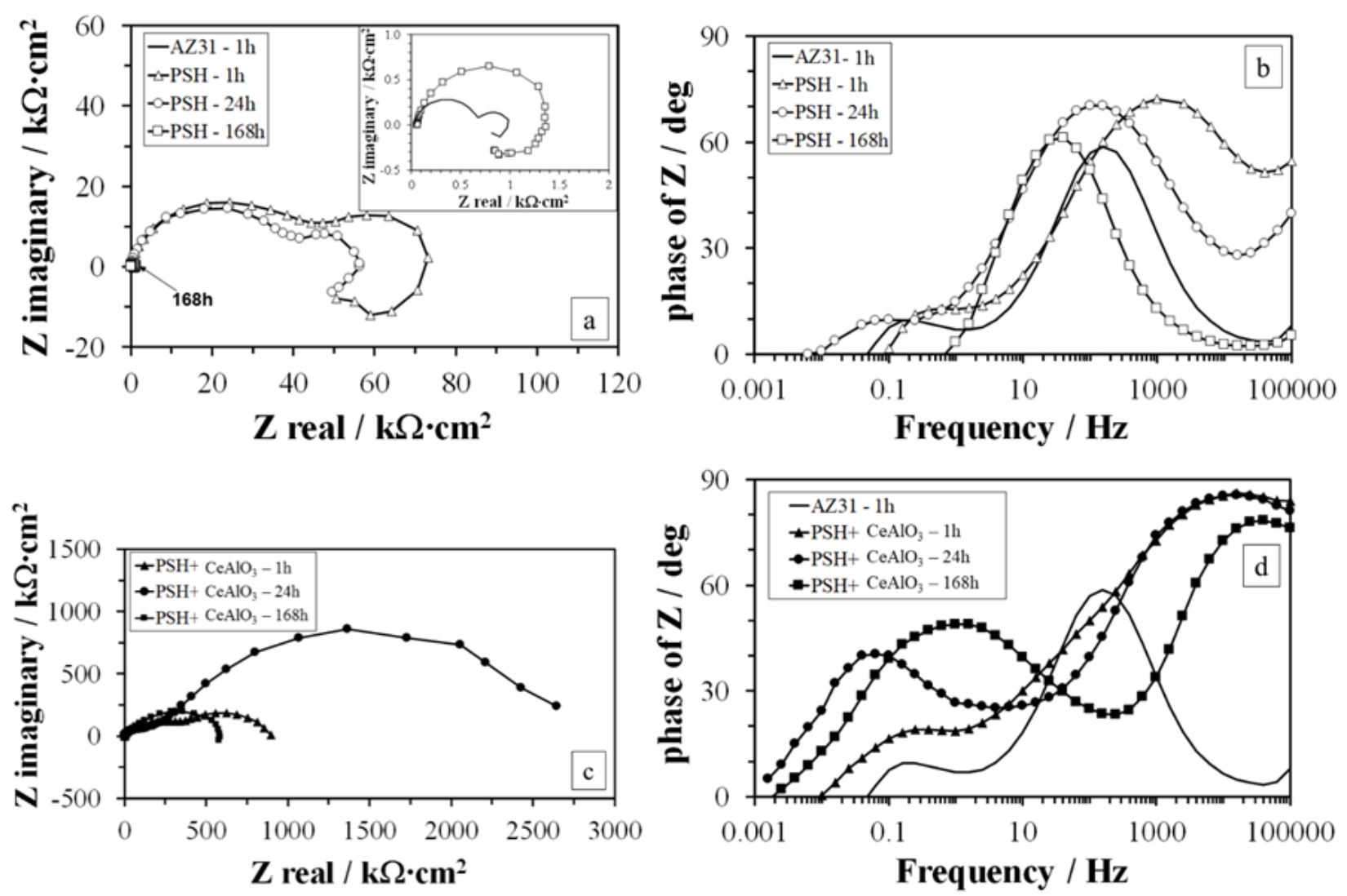

Figure 4. EIS spectra (Nyquist and phase angle plot) of AZ31 both untreated and treated by PSH during immersion in $0.1 \mathrm{M} \mathrm{NaCl}$. (a,b) refer to the plain coating, while (c,d) to the $\mathrm{CeAlO}_{3}$ loaded one.

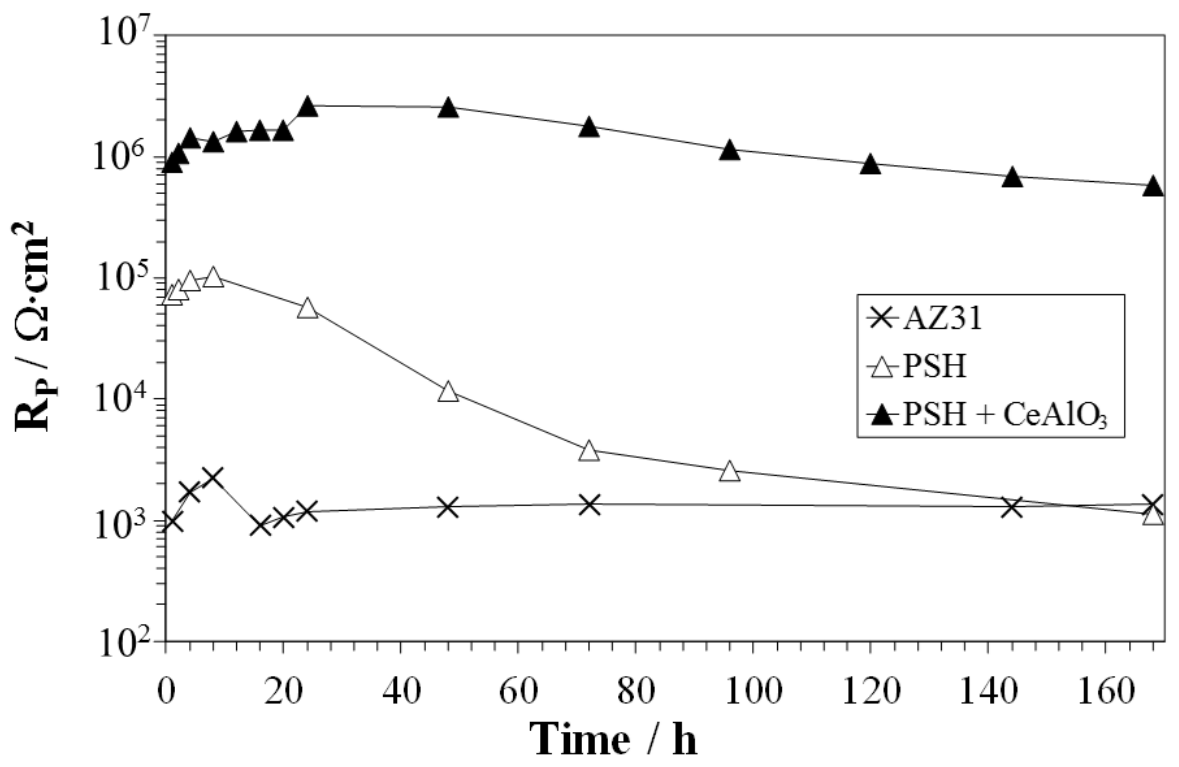

Figure 5. Time dependence of $R_{\mathrm{p}}$ values obtained during immersions in $0.1 \mathrm{M} \mathrm{NaCl}$ of AZ31 electrodes and PSH treated AZ31 electrodes, unloaded or loaded with $\mathrm{CeAlO}_{3}$ nanoparticles. 

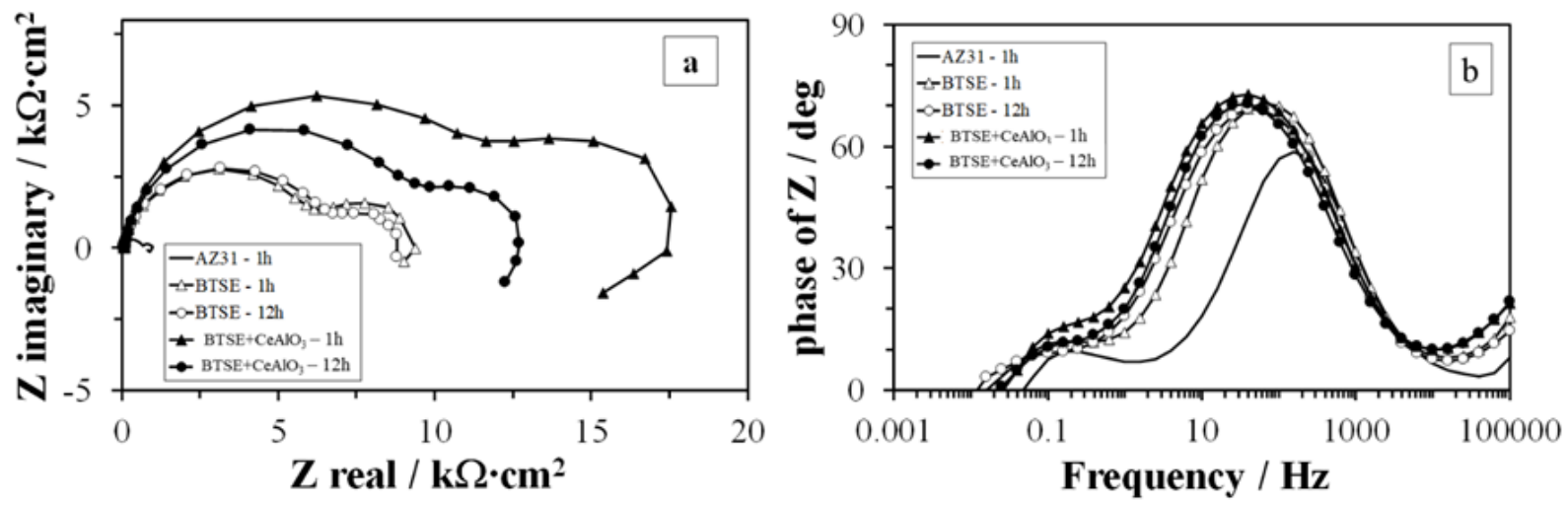

Figure 6. EIS spectra (Nyquist and phase angle plot) recorded in $0.1 \mathrm{M} \mathrm{NaCl}$ on BTSE treated AZ31 electrodes in the absence or presence of $\mathrm{CeAlO}_{3}$ nanoparticles.

After $1 \mathrm{~h}$ immersion, nanoparticle loading in PSMA increased $R_{\mathrm{p}}$ value to around $100 \mathrm{k} \Omega \cdot \mathrm{cm}^{2}$, mainly by enlarging the $I f$ loop. Figure 7 shows that three $\tau$ are present also in this coating type, more evident after $12 \mathrm{~h}$. The nanoparticles retarded the coating decay, because after $24 \mathrm{~h}$, a $R_{\mathrm{p}}$ value of $35 \mathrm{k} \Omega \cdot \mathrm{cm}^{2}$ was obtained, significantly higher than that of the unloaded coating $\left(4.4 \mathrm{k} \Omega \cdot \mathrm{cm}^{2}\right) . \mathrm{CeAlO}_{3}$ addition also improved the efficiency of VS coatings (where again three $\tau$ are distinguished) in the first 2-4 hours of testing (Figure 8), but successively $R_{\mathrm{p}}$ values of unloaded and loaded VS were the same (Figure 9 ).
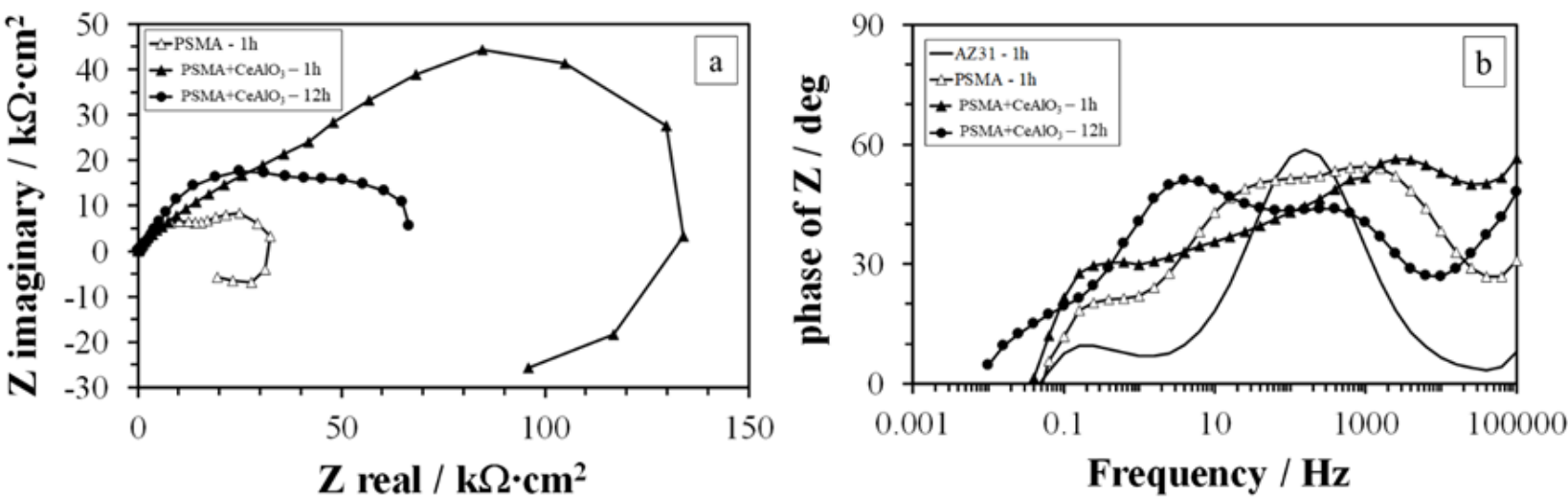

Figure 7. EIS spectra (Nyquist and phase angle plot) recorded in $0.1 \mathrm{M} \mathrm{NaCl}$ on PSMA treated $\mathrm{AZ31}$ electrodes in the absence or presence of $\mathrm{CeAlO}_{3}$ nanoparticles.

Only PSH-based spectra were subjected to further analysis by fitting with the Electrical Equivalent Circuit (EEC) reported in Figure 10, already used in a previous work on the same system [11]. The EEC contains $R_{0}$, the resistance of the contacts, wires and solution between the reference tip and the working electrode, and three $R-\mathrm{CPE}$ couples:

a. $R_{\mathrm{PO}}-\mathrm{CPE}_{\mathrm{C}}$, where $R_{\mathrm{PO}}$ is the resistance of the pores in the silane coating filled by the electrolytic solution and $\mathrm{CPE}_{\mathrm{C}}$ is correlated to the silane layer capacitance, 
b. $R_{\mathrm{CT}}-\mathrm{CPE}_{\mathrm{DL}}$, where $R_{\mathrm{CT}}$ is the resistance associated with the corrosion process at the bottom of the coating pores and $\mathrm{CPE}_{\mathrm{DL}}$ is related to the double layer capacitance associated to charge transfer at the pore bottom, and

c. $R_{\mathrm{DIFF}}-\mathrm{CPE}_{\mathrm{DIFF}}$, where $R_{\mathrm{DIFF}}$ and $\mathrm{CPE}_{\mathrm{DIFF}}$ are connected to a diffusion process affecting corrosion rates.

The $R_{\mathrm{DIFF}}-\mathrm{CPE}_{\mathrm{DIFF}}$ couple was used to describe the $I f \tau$ of the spectra [47], while the $h f$ capacitive semicircle was interpreted as the envelope of two $\tau$ related to the coating dielectric behaviour and the corrosion process [11] and was closely fitted by the couples $\mathrm{R}_{\mathrm{PO}}-\mathrm{CPE}_{\mathrm{C}}$ and $R_{\mathrm{CT}}-\mathrm{CPE}_{\mathrm{DL}}$.
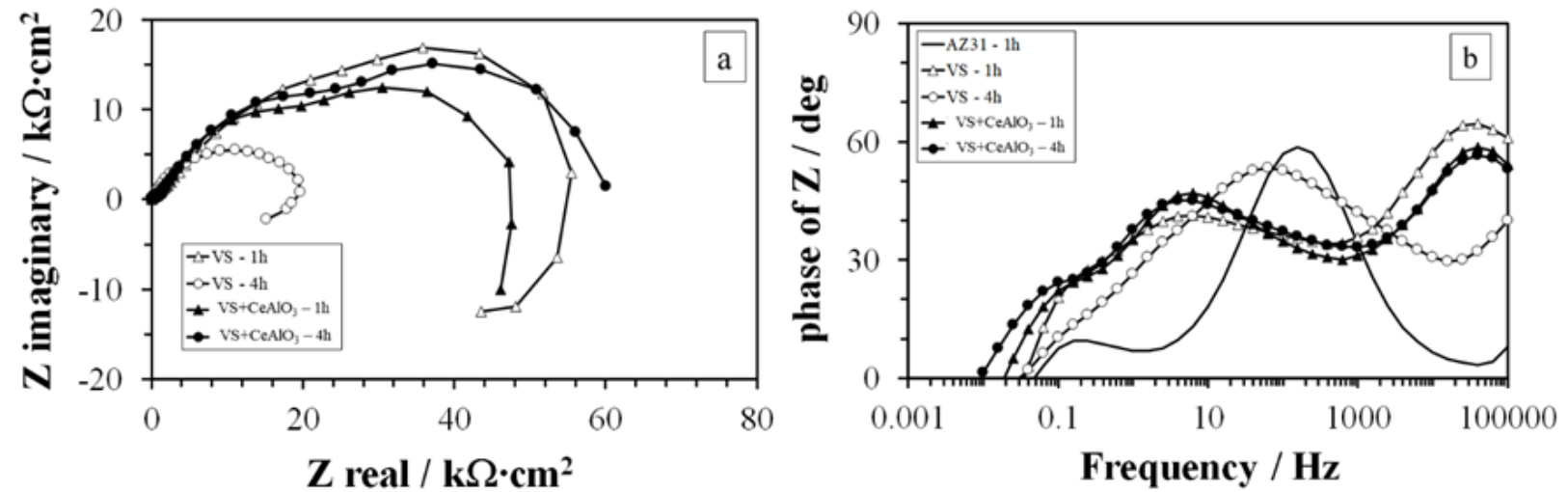

Figure 8. EIS spectra (Nyquist and phase angle plot) recorded in $0.1 \mathrm{M} \mathrm{NaCl}$ on VS treated AZ31 electrodes in the absence or presence of $\mathrm{CeAlO}_{3}$ nanoparticles.
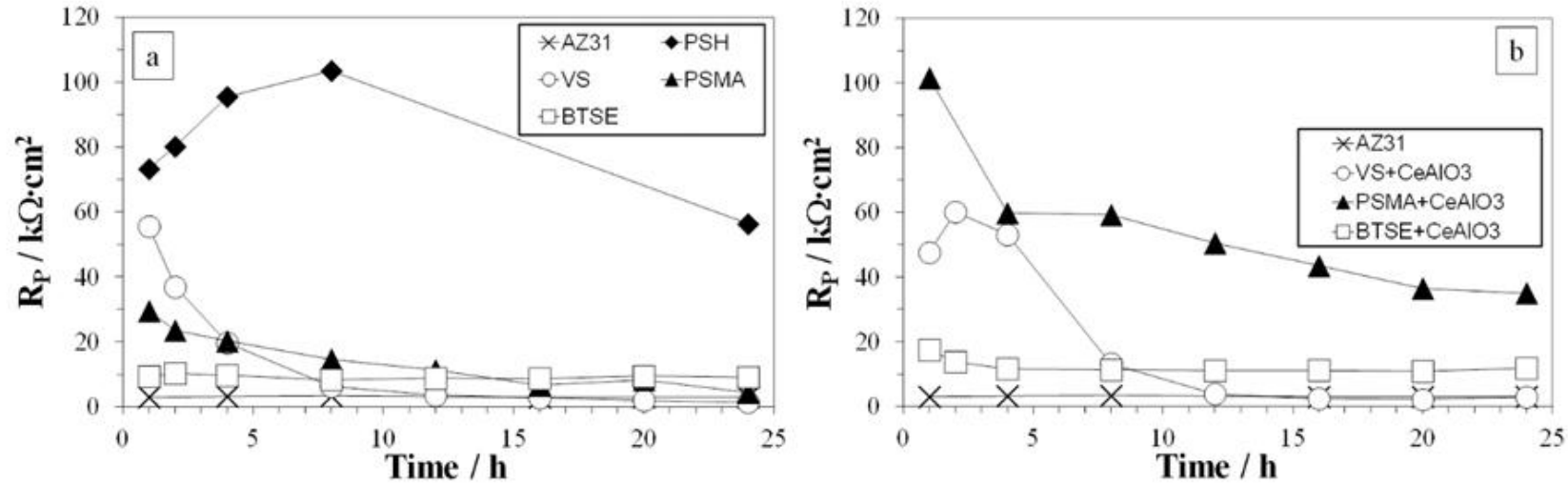

Figure 9. Time dependence of $R_{\mathrm{p}}$ values obtained during immersions in $0.1 \mathrm{M} \mathrm{NaCl}$ of AZ31 electrodes treated by various silanes, unloaded (a) or loaded (b) with $\mathrm{CeAlO}_{3}$ nanoparticles.

The CPE elements were used instead of pure capacitances, $C$, to take into account the non-ideal behaviour of the system, but then $C$ values were extracted from $\mathrm{CPE}$ values, as described in [48]. 


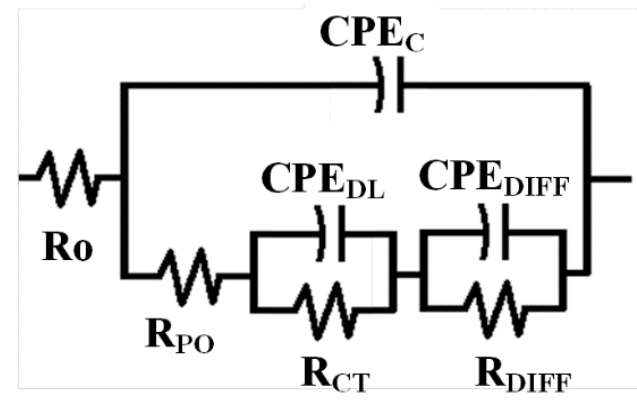

Figure 10. Electrical Equivalent Circuit (EEC) adopted for fitting impedance spectra analysis.

The analysis of the fitting parameters shows that in PSH coating $R_{\mathrm{PO}}$, characterized by an initial value of $0.5 \mathrm{k} \Omega \cdot \mathrm{cm}^{2}$, decreased rather quickly to $0.08 \mathrm{k} \Omega \cdot \mathrm{cm}^{2}$ after $48 \mathrm{~h}$, while in the same time interval $C_{\mathrm{C}}$ increased from 0.023 to $0.25 \mu \mathrm{F} \cdot \mathrm{cm}^{-2}$, due to the entrance of the aggressive solution (Figure 11). At longer immersion time, the fitting analysis clearly showed that the $\tau$ corresponding to the $R_{\mathrm{PO}}-\mathrm{CPE}_{\mathrm{C}}$ couple no more influenced the spectra, likely due to a significant PSH coating degradation. On the contrary, in the presence of $\mathrm{CeAlO}_{3}$, even if $R_{\mathrm{PO}}$ decreased from $55 \mathrm{k} \Omega \cdot \mathrm{cm}^{2}$ to $7 \mathrm{k} \Omega \cdot \mathrm{cm}^{2}$, during $168 \mathrm{~h}$, it remained quite high throughout the test, likely due to the presence of a relatively low amount of pores and defects and/or to a higher coating thickness. The low defectiveness and/or high thickness is confirmed by the lower $C_{\mathrm{C}}$ values of $\mathrm{CeAlO}_{3}$-containing $\mathrm{PSH}$, in comparison to those of plain PSH (as an example, after $1 \mathrm{~h}$ immersion, $C_{\mathrm{C}}$ was $8 \mathrm{nF} \cdot \mathrm{cm}^{-2}$ for loaded $\mathrm{PSH}$ coating and $26 \mathrm{nF} \cdot \mathrm{cm}^{-2}$ for the unloaded one).
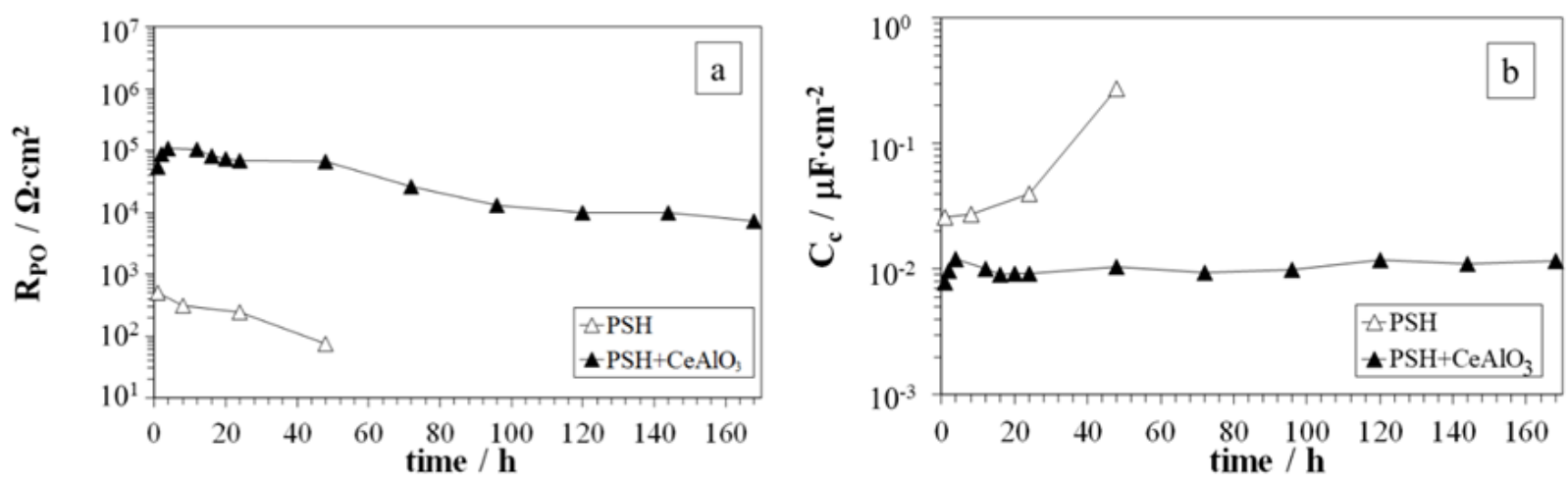

Figure 11. Trend of $R_{\mathrm{PO}}$ and $C_{\mathrm{C}}$ versus time for AZ31 electrodes treated by the PSH, unloaded or loaded with $\mathrm{CeAlO}_{3}$ nanoparticles.

$R_{\mathrm{CT}}$ and $C_{\mathrm{DL}}$ trends are presented in Figure 12. In the case of plain PSH coating, $R_{\mathrm{CT}}$ gradually shifted from $44 \mu \mathrm{F} \cdot \mathrm{cm}^{-2}$ (after $1 \mathrm{~h}$ immersion) to $1 \mathrm{k} \Omega \cdot \mathrm{cm}^{2}$ (after $168 \mathrm{~h}$ ), while $C_{\mathrm{DL}}$ increased from 0.11 to $23 \mu \mathrm{F} \cdot \mathrm{cm}^{-2}$. With the addition of $\mathrm{CeAlO}_{3}, R_{\mathrm{CT}}$ was higher $\left(260 \mathrm{k} \Omega \cdot \mathrm{cm}^{2}\right.$, at $\left.1 \mathrm{~h}\right)$ and $C_{\mathrm{DL}}$ lower $\left(0.05 \mu \mathrm{F} \cdot \mathrm{cm}^{-2}\right)$ than the same parameters in PSH, due to the smaller interconnected porosity of the loaded coating which induced a decrease in the metal surface area in contact with the aggressive solution at the pore bottom. The 
nanoparticles presence also slowed down the rate of coating degradation. In fact, even if $R_{\mathrm{CT}}$ decreased with time, it still maintained values as high as $44 \mathrm{k} \Omega \cdot \mathrm{cm}^{2}$ after $168 \mathrm{~h}$. Moreover, $C_{\mathrm{DL}}$ (a parameter quite sensitive to the increase in the attacked surface) showed very low values for $48 \mathrm{~h}\left(0.19 \mu \mathrm{F} \cdot \mathrm{cm}^{-2}\right.$ ), then it increased (to $3 \mu \mathrm{F} \cdot \mathrm{cm}^{-2}$, after $168 \mathrm{~h}$ ), but always remained lower than the corresponding values in pure silane.
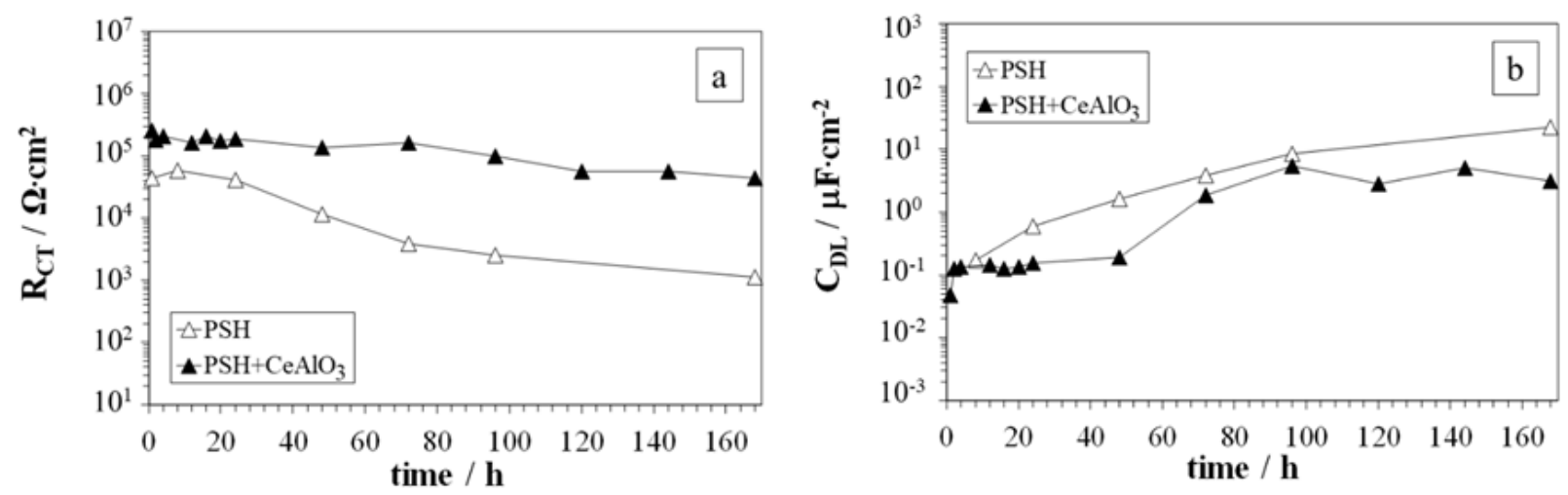

Figure 12. Trend of $R_{\mathrm{CT}}$ and $C_{\mathrm{DL}}$ versus time for AZ31 electrodes treated by the PSH, unloaded or loaded with $\mathrm{CeAlO}_{3}$ nanoparticles.

In the loaded conversion coating, diffusion afforded a more significant hinder to the corrosion process than in plain PSH. In fact, nanoparticle addition determined quite high and initially increasing $R_{\mathrm{DIFF}}$ values as well as low and constant $C_{\mathrm{DIFF}}$ values (Figure 13), while in plain PSH this $\tau$ disappeared for immersion times longer than $24 \mathrm{~h}$.
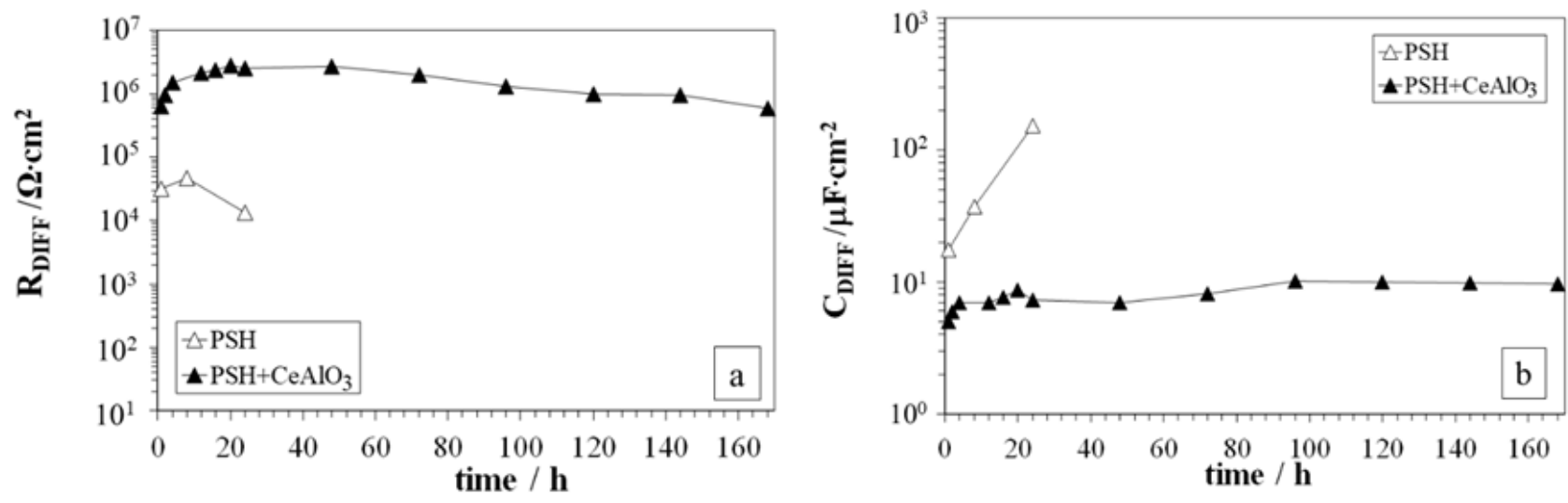

Figure 13. Trend of $R_{\mathrm{DIFF}}$ and $C_{\mathrm{DIFF}}$ versus time for $\mathrm{AZ} 31$ electrodes treated by the $\mathrm{PSH}$, unloaded or loaded with $\mathrm{CeAlO}_{3}$ nanoparticles.

In Figure 14, the SEM images allow to calculate the thickness of the double silane layer in the absence (Figure 14a) and presence of the $\mathrm{CeAlO}_{3}$ nanoparticles (Figure 14c). The SEM-EDS elemental map in the region of Figure 14a delimited by the pink rectangle is reported in Figure 14b. This latter Figure helps to interpret the geometry of the observed coupled coated specimens, where the two coupled $\mathrm{Si}$ - and $\mathrm{S}$-rich silane layers are 
sandwiched between two Mg-rich AZ31 substrates. This arrangement allows measuring a thickness of $3.5 \pm 0.5 \mu \mathrm{m}$ for the PSH layers and $5.6 \pm 0.6 \mu \mathrm{m}$ for PSH with $\mathrm{CeAlO}_{3}$ nanoparticles. The higher thickness of the latter coating agrees with the high $R_{\mathrm{PO}}$ and the low $C_{\mathrm{C}}$ values measured in the presence of the nanoparticles.
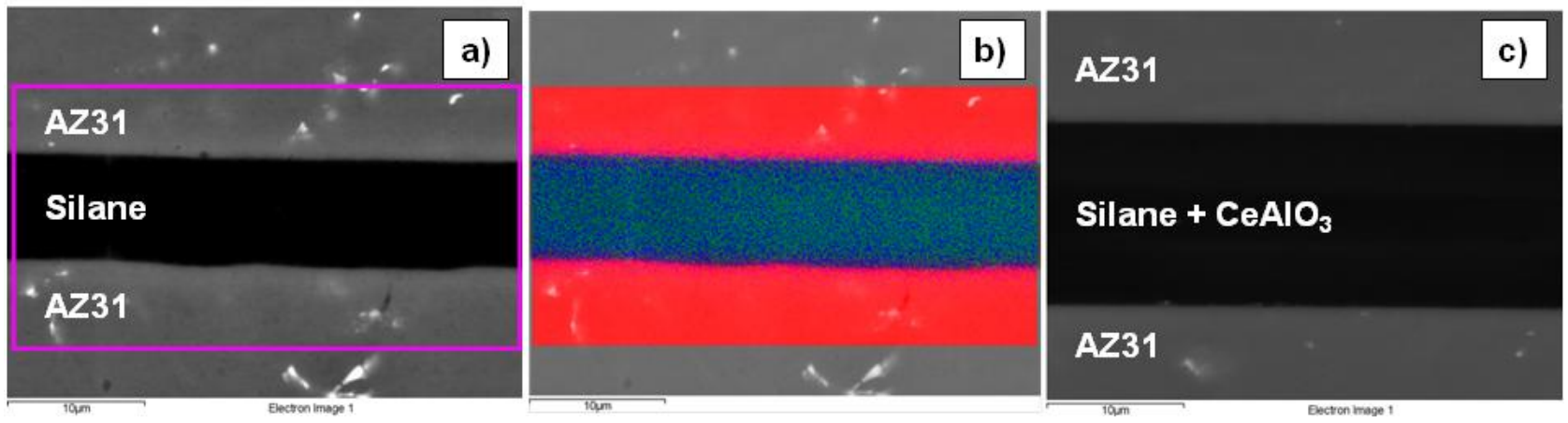

Figure 14. SEM images of the AZ31 samples covered by the silane layer unloaded (a) and loaded with $\mathrm{CeAlO}_{3}$ nanoparticles (c) and EDS map (b) obtained on sample (a) showing $\mathrm{Mg}$ (red), Si (green) and S (blue) distributions.

\section{Discussion}

During the immersion of AZ31 in $0.1 \mathrm{~N} \mathrm{NaCl}$, a layer of corrosion products (mainly magnesium oxide-hydroxides) grew on the metal surface, exerting a scarce protection towards the alloy dissolution rate. The corrosion resistance of this alloy was improved by the treatment with silane conversion coatings. In comparison to unprotected AZ31 specimen, the silane treated specimens showed a diminution in the polarization currents which was attributed to a reduction in the metal surface area available for the corrosion process at the coating pore bottom. The more significant decrease in the cathodic currents indicated a higher tendency of the silane coating to form on the cathodic sites of AZ31 alloy. In the case of PSH, where an evident decrease was also observed in the anodic polarization currents, the formation of the conversion layer could equally take place on both cathodic and anodic sites.

On AZ31 Mg alloy, PSH was the most efficient among the tested silanes, followed by the vinyl derivatives (VS and PSMA), and finally by BTSE. VS, BTSE, PSMA conversion coatings allowed the penetration of the aggressive electrolytic solutions up to the metal surface within a short time interval (few hours), so that the corrosion process quickly started. PSH coating maintained a high degree of protection for at least $24 \mathrm{~h}$, but successively it gradually lost its protective effects which were almost completely annulled after $168 \mathrm{~h}$.

The addition of $\mathrm{CeAlO}_{3}$ nanoparticles increased the protectiveness of all conversion coatings and such increase was strictly dependent on their initial efficiency: the more efficient the original silane layer, the greater the nanoparticle effects. Therefore, this improvement was particularly relevant in the case of PSH, but only limited for BTSE. The 
natural barrier action of PSH was noticeably increased by $\mathrm{CeAlO}_{3}$ nanoparticles and the protective performance remained stable for more than one week. A similar but weaker effect was induced by nanoparticles on PSMA too.

In the literature, it was found that nanoparticle charging improves the barrier properties of silane coatings by increasing their thickness [17, 22, 25], plugging porosity $[17,22]$ and enhancing the polymer cross-linking [16]. In the present research, SEM analysis showed that the lower $C_{\mathrm{C}}$ and higher $R_{\mathrm{PO}}$ values of the $\mathrm{CeAlO}_{3}$ loaded PSH layer, compared to those of the unloaded silane, were linked to the development of a thicker coating (Figure 14), but were also related to a diminution in the interconnected porosity. In fact, the higher $R_{\mathrm{CT}}$ and lower $C_{\mathrm{DL}}$ values (Figure 12) suggested a decrease in the metal surface area in contact with the electrolyte through the pores, likely due to pore plugging effect and increased coating reticulation induced by nanoparticles. The difficulty in the electrolyte penetration to the metal surface was a reason of better coating durability.

In the case of ceria-containing silane coatings, the outstanding properties of corrosion protection described in the literature $[14,49]$ were also ascribed to the onset of a specific inhibition effect due to the release of cerium ions and the formation of a very corrosionresistant mixed $\mathrm{Ce}-\mathrm{Mg}$ oxide-hydroxide layer at the metal/coating interface. Concerning $\mathrm{Ce} \mathrm{AlO}_{3}$ addition, it is likely that dissolution of nanoparticles occurred a certain extent with the release of $\mathrm{Ce}^{+3}$ ions into the solution, thus inducing the well-known inhibiting effects of cerium salts $[13-15,18,26,28,41,50]$. Moreover, the limited defectiveness of the most efficient PSH coating likely favored an easier pore-plugging action by the highly protective mixed $\mathrm{Mg}-\mathrm{Ce}$ oxide-hydroxides, so contributing to the initial increase in $R_{\mathrm{PO}}$ noticed in $\mathrm{CeAlO}_{3}$ loaded $\mathrm{PSH}$ coating.

In the present research, it was found that nanoparticles addition clearly inhibited the anodic reaction and meanwhile enlarged the $I f$ capacitive loop of EIS spectra. In fact, due to $\mathrm{CeAlO}_{3}$ nanoparticle addition a slow outward diffusion of $\mathrm{Mg}^{++}$ions from the metallic surface to the solution occurred due to both a thicker PSH layer formation and likely a stabilization of the rather protective $\mathrm{Mg}-\mathrm{Ce}$ oxide-hydroxide corrosion products. The obtained values of the $\mathrm{n}$ exponent of $\mathrm{CPE}_{\mathrm{DIFF}}$, close to $0.5-0.6$, supported the attribution of the $l f \tau$ to diffusion.

\section{Conclusions}

1. $\mathrm{CeAlO}_{3}$ nanoparticles improved the protective performances of the silane conversion coatings: the more efficient the original silane layer, the greater the effects.

2. $\mathrm{CeAlO}_{3}$ nanoparticle loaded $\mathrm{PSH}$ exerted the highest protective action against AZ31 corrosion in $0.1 \mathrm{~N} \mathrm{NaCl}$. This protectiveness lasted during the whole $168 \mathrm{~h}$ test.

3. SEM analysis and EIS spectra evidenced an increase in the layer thickness and a decrease in its porosity after addition of $\mathrm{CeAlO}_{3}$ nanoparticles in PSH.

4. $\mathrm{CeAlO}_{3}$ nanoparticle addition markedly limited diffusion steps, which in turn mainly slowed down the anodic reaction of the corrosion process. 


\section{References}

1. J.E. Gray and B. Luan, Protective coatings on magnesium and its alloys - a critical review, J. Alloys Compd., 2002, 336, 88-113. doi: 10.1016/S0925-8388(01)01899-0

2. Yu.I. Kuznetsov, A.M. Semiletov and A.A. Chirkunov, Inhibition of magnesium corrosion by triazoles, Int. J. Corros. Scale Inhib., 2016, 5, no. 1, 31-49. doi: 10.17675/2305-6894-2016-5-1-3

3. F. Zucchi, V. Grassi and F. Zanotto, Sodium monocarboxylates as inhibitors of AZ31 alloy corrosion in a synthetic cooling water, Mater. Corros., 2009, 60, 199-205. doi: $10.1002 / \mathrm{maco} .200805045$

4. A. Frignani, V. Grassi, F. Zanotto and F. Zucchi, Inhibition of AZ31 Mg alloy corrosion by anionic surfactants, Corros. Sci., 2012, 63, 29-39. doi: 10.1016/j.corsci.2012.05.012

5. A.A. Chirkunov and M.L. Zheludkevich, Corrosion inhibition of Elektron WE43 magnesium alloy in $\mathrm{NaCl}$ solution, Int. J. Corros. Scale Inhib., 2018, 7, no. 3, 376-389. doi: $10.17675 / 2305-6894-2018-7-3-8$

6. V.A. Ogorodnikova, Yu.I. Kuznetsov, A.A. Chirkunov and A.M. Semiletov, Inhibition of anodic dissolution of $\mathrm{Mg} 90$ alloy by adsorption layers of higher carboxylic acids, Int. J. Corros. Scale Inhib., 2018, 7, no. 2, 260-270. doi: 10.17675/2305-6894-2018-7$2-11$

7. A. Frignani, V. Grassi, F. Zucchi and F. Zanotto, Mono-carboxylate conversion coatings for AZ31 Mg alloy protection, Mater. Corros., 2011, 62, 995-1002. doi: 10.1002/maco.200905615

8. F. Zucchi, A. Frignani, V. Grassi, G. Trabanelli and C. Monticelli, Stannate and permanganate conversion coatings on AZ31 magnesium alloy, Corros. Sci., 2007, 49, 4542-4552. doi: 10.1016/i.corsci.2007.04.011

9. S.-Y. Jian, Y.-R. Chu and C.-S. Lin, Permanganate conversion coating on AZ31 magnesium alloys with enhanced corrosion resistance, Corros. Sci., 2015, 93, 301-309. Doi: 10.1016/j.corsci.2015.01.040

10. A.S. Hamdy and D.P. Butt, Novel smart stannate based coatings of self-healing functionality for AZ91D magnesium alloy, Electrochem. Acta, 2013, 97, 296-303. doi: 10.1016/j.electacta.2013.02.108

11. F. Zucchi, V. Grassi, A. Frignani, C. Monticelli and G. Trabanelli, Influence of a silane treatment on the corrosion resistance of a WE43 magnesium alloy, Surf. Coat. Technol., 2006, 200, 4136-4143. doi: 10.1016/j.surfcoat.2005.02.073

12. F. Zucchi, A. Frignani, V. Grassi, A. Balbo and G. Trabanelli, Organo-silane coatings for AZ31 magnesium alloy corrosion protection, Mater. Chem. Phys., 2008, 110, 263-268. doi: $10.1016 /$ j.matchemphys.2008.02.015

13. F. Zanotto, V. Grassi, A. Frignani and F. Zucchi, Protection of the AZ31 Magnesium alloy with cerium modified silane coating, Mat. Chem. Phys., 2011, 129, 1-8. doi: $\underline{10.1016 / j . m a t c h e m p h y s .2011 .05 .013}$ 
14. M.F. Montemor and M.G.S. Ferreira, Electrochemical study of modified bis [triethoxysylilpropyl] tetrasulphide silane films applied on the AZ31 Mg alloy, Electrochim. Acta, 2007, 52, 7486-7495. doi: 10.1016/j.electacta.2006.12.086

15. M.F. Montemor and M.G.S. Ferreira, Analytical and microscopic characterization of modified bis-[triethoxysylilpropyl] tetrasulphide silane films on magnesium AZ31 substrates, Prog. Org. Coat., 2007, 60, 228-237. doi: 10.1016/j.porgcoat.2007.07.019

16. M.F. Montemor, R. Pinto and M.G.S. Ferreira, Chemical composition and corrosion protection of silane films modified with $\mathrm{CeO}_{2}$ nanoparticles, Electrochim. Acta, 2009, 54, 5179-5189. doi: $10.1016 /$ j.electacta.2009.01.053

17. M.F. Montemor, A.M. Cabral, M.L. Zheludkevich and M.G.S. Ferreira, The corrosion resistance of hot dip galvanized steel pretreated with Bis-functional silanes modified with microsilica, Surf. Coat. Technol., 2006, 200, 2875-2885. doi: 10.1016/j.surfcoat.2004.11.012

18. M.F. Montemor and M.G.S. Ferreira, Cerium salt activated nanoparticles as fillers for silane films: Evaluation of the corrosion inhibition performance on galvanised steel substrates, Electrochim. Acta, 2007, 52, 6976-6987. doi: 10.1016/j.electacta.2007.05.022

19. M.F. Montemor, W. Trabelsi， S.V. Lamaka， K.A. Yasakau， M.L. Zheludkevich, A.C. Bastos and M.G.S. Ferreira, The synergistic combination of bis-silane and $\mathrm{CeO}_{2} \cdot \mathrm{ZrO}_{2}$ nanoparticles on the electrochemical behaviour of galvanised steel in $\mathrm{NaCl}$ solutions, Electrochim. Acta, 2008, 53, 5913-5922. doi: 10.1016/j.electacta.2008.03.069

20. R.Z.Zand, V. Flexer, M. De Keersmaecker, K. Verbeken and A. Adriaens, Effects of Activated Ceria and Zirconia Nanoparticles on the Protective Behaviour of Silane Coatings in Chloride Solutions, Int. J. Electrochem. Sci., 2015, 10, 997-1014.

21. R.Z.Zand, V. Flexer, M. De Keersmaecker, K. Verbeken and A. Adriaens, Selfhealing silane coatings of cerium salt activated nanoparticles, Mater. Corros., 2016, 67, 693-701. doi: $10.1002 /$ maco.201508670

22. P.H. Suegama, A.A.C. Recco, A.P. Tschiptschin and I.V. Aoki, Influence of silica nanoparticles added to an organosilane film on carbon steel electrochemical and tribological behaviour, Prog. Org. Coat., 2007, 60, 90-98. doi: 10.1016/j.porgcoat.2007.07.006

23. C. Zhou, X. Lu, Z. Xin, J. Liu and Y.Zhang, Polybenzoxazine/SiO ${ }_{2}$ nanocomposite coatings for corrosion protection of mild steel, Corros. Sci., 2014, 80, 269-275. doi: 10.1016/j.corsci.2013.11.042

24. C. Chen, S. Dong, R. Hou, J. Hu, P. Jiang, C. Ye, R. Du and C. Lin, Insight into the anti-corrosion performance of electrodeposited silane $/$ nano- $\mathrm{CeO}_{2}$ film on carbon steel, Surf. Coat. Technol., 2017, 326, 183-191. doi: 10.1016/j.surfcoat.2017.06.031 
25. V. Palanivel, D. Zhu and W.J. van Ooij, Nanoparticle-filled silane films as chromate replacements for aluminum alloys, Prog. Org. Coat., 2003, 47, 384-392, doi: 10.1016/j.porgcoat.2003.08.015

26. M.L. Zheludkevich， R. Serra，M.F. Montemor，K.A. Yasakau， I.M.M. Salvado and M.G.S. Ferreira, Nanostructured sol-gel coatings doped with cerium nitrate as pretreatments for AA2024-T3: Corrosion protection performance, Electrochim. Acta, 2005, 51, 208-217. doi: 10.1016/j.electacta.2005.04.021

27. M.L. Zheludkevich, R. Serra, M.F. Montemor, I.M.M. Salvado and M.G.S. Ferreira, Corrosion protective properties of nanostructured sol-gel hybrid coatings to AA2024T3, Surf. Coat. Technol., 2006, 200, 3084-3094. doi: 10.1016/j.surfcoat.2004.09.007

28. N.C. Rosero-Navarro, S.A. Pellice, A. Duran and M. Aparicio, Effects of Cecontaining sol-gel coatings reinforced with $\mathrm{SiO}_{2}$ nanoparticles on the protection of AA2024, Corros. Sci., 2008, 50, 1283-1291. doi: 10.1016/j.corsci.2008.01.031

29. F. Brusciotti, A. Batan, I. De Graeve, M. Wenkin, M. Biessemans, R. Willem, F. Reniers, J.J. Pireaux, M. Piens, J. Vereecken and H. Terryn, Characterization of thin water-based silane pre-treatments on aluminium with the incorporation of nanodispersed $\mathrm{CeO}_{2}$ particles, Surf. Coat. Technol., 2010, 205, 603-613. doi: 10.1016/j.surfcoat.2010.07.052

30. M. Niknahad and V. Mannari, Corrosion protection of aluminum alloy substrate with nano-silica reinforced organic-inorganic hybrid coatings, J. Coat. Technol. Res., 2016, 13, 1035-1046. doi: 10.1007/s11998-016-9814-4

31. M. Zaharescu， L. Predoana，A. Barau，D. Raps，F. Gammel， N.C. Rosero-Navarro, Y. Castro, A. Duran and M. Aparicio, $\mathrm{SiO}_{2}$ based hybrid inorganic-organic films doped with $\mathrm{TiO}_{2}-\mathrm{CeO}_{2}$ nanoparticles for corrosion protection of AA2024 and $\mathrm{Mg}$ AZ31B alloys, Corros. Sci., 2009, 51, 1998-2005. doi: 10.1016/j.corsci.2009.05.022

32. H. Ashassi-Sorkhabi, S. Moradi-Alavian, R. Jafari, A. Kazempour and E. Asghari, Effect of amino acids and montmorillonite nanoparticles on improving the corrosion protection characteristics of hybrid sol-gel coating applied on AZ91 Mg alloy, Mater. Chem. Phys., 2019, 225, 298-308. doi: 10.1016/j.matchemphys.2018.12.059

33. R. Zhu, J. Zhang, C. Chang, S. Gao and N. Ni, Effect of silane and zirconia on the thermal property of cathodic electrophoretic coating on AZ31 magnesium alloy, J. Magnesium Alloys, 2013, 1, 235-241. doi: 10.1016/j.jma.2013.08.001

34. F. Zanotto, V. Grassi, A. Frignani, C. Monticelli, A. Balbo and F. Zucchi, Corrosion behaviour of AZ31 Magnesium alloy pre-treated with silane solutions modified with nano-particle oxides, Proceedings EUROCORR 2009, Paper SS 5-0-8227, CD-ROM, Eurocorr 2009, Nice (F), 6-10 September 2009.

35. A.F. Scott, J.E. Gray-Munro and J.L. Shepherd, Influence of coating bath chemistry on the deposition of 3-mercaptopropyl trimethoxysilane films deposited on magnesium alloy, J. Colloid Interface Sci., 2010, 343, 474-483. doi: 10.1016/j.jcis.2009.11.062 
36. J. Kim, K.C. Wong, P.C. Wong, S.A. Kulinich, J.B. Metson and K.A.R. Mitchell, Characterization of AZ91 magnesium alloy and organosilane adsorption on its surface, Appl. Surf. Sci., 2007, 253, 4197-4207. doi: 10.1016/j.apsusc.2006.09.030

37. A. Mandelli, M. Bestetti, A. Da Forno, N. Lecis, S.P. Trasatti and M. Trueba, A composite coating for corrosion protection of AM60B magnesium alloy, Surf. Coat. Technol., 2011, 205, 4459-4465. doi: 10.1016/j.surfcoat.2011.03.066

38. P.C. Banerjee and R.K.S. Raman, Electrochemical impedance spectroscopic investigation of the role of alkaline pre-treatment in corrosion resistance of a silane coating on magnesium alloy, ZE41, Electrochim. Acta, 2011, 56, 3790-3798. doi: 10.1016/j.electacta.2011.02.050

39. Y. Liu, D. Sun, H. You and J.S. Chung, Corrosion resistance properties of organicinorganic hybrid coatings on 2024 aluminum alloy, Appl. Surf. Sci., 2005, 246, 82-89. doi: $10.1016 /$ j.apsusc. 2004.10 .040

40. B.N. Zand, M. Mahdavian, Evaluation of the effect of vinyltrimethoxysilane on corrosion resistance and adhesion strength of epoxy coated AA1050, Electrochim. Acta, 2007, 52, 6438-6442. doi: 10.1016/j.electacta.2007.04.043

41. X. Zhong, Q. Li, J. Hu, X. Yang, F. Luo and Y. Dai, Effect of cerium concentration on microstructure, morphology and corrosion resistance of cerium-silica hybrid coatings on magnesium alloy AZ91D, Prog. Org. Coat., 2010, 69, 52-56. doi: 10.1016/j.porgcoat.2010.05.004

42. J. Hu, Q. Li, X. Zhong, L. Li and L. Zhang, Organic coatings silane-based for AZ91D magnesium alloy, Thin Solid Films, 2010, 519, 1361-1366. doi: $\underline{10.1016 / j . t s f .2010 .09 .014}$

43. I. Milošev, Ž. Jovanović, J.B. Bajat, R. Jančić-Heinemann and V.B. MiškovićStanković, Surface analysis and electrochemical behaviour of Aluminium pretreated by Vinyltriethoxysilane films in mild $\mathrm{NaCl}$ solution, J. Electrochem. Soc., 2012, 159, C303-C311. doi: 10.1149/2.042207jes

44. J. Flis and M. Kanosa, Electrochemical and surface analytical study of vinyl-triethoxy silane films on iron after exposure to air, Electrochim. Acta, 2006, 51, 2338-2345. doi: 10.1016/j.electacta.2005.01.065

45. Electrochemical Impedance software ZsimpWin, Version 3.22, 2010.

46. G. Baril, G. Galicia, C. Deslouis, N. Pebere, B. Tribollet and V. Vivier, An Impedance Investigation of the Mechanism of Pure Magnesium Corrosion in Sodium Sulfate Solutions, J. Electrochem. Soc., 2007, 154, C108-113. doi: 10.1149/1.2401056

47. M.F. Montemor, W. Trabelsi, M. Zheludkevich and M.G.S. Ferreira, Modification of bis-silane solutions with rare-earth cations for improved corrosion protection of galvanized steel substrates, Prog. Org. Coat., 2006, 57, 67-77. doi: 10.1016/j.porgcoat.2006.06.009 
48. C.H. Hsu and F. Mansfeld, Concerning the conversion of the constant phase element parameter $\mathrm{Y}_{0}$ into a capacitance, Corrosion, 2001, 57, 747-748. doi: $10.5006 / 1.3280607$

49. A.L. Rudd, C.B. Breslin and F. Mansfeld, The corrosion protection afforded by rare earth conversion coatings applied to magnesium, Corros. Sci., 2000, 42, 275-288. doi: 10.1016/S0010-938X(99)00076-1

50. A.M. Cabral, W. Trabelsi, R. Serra, M.F. Montemor, M.L. Zheludkevich and M.G.S. Ferreira, The corrosion resistance of hot dip galvanized steel and AA2024-T3 pre-treated with bis-[triethoxysilylpropyl]tetrasulfide solutions doped with $\mathrm{Ce}\left(\mathrm{NO}_{3}\right)_{3}$, Corros. Sci., 2006, 48, 3740-3758. doi: 10.1016/j.corsci.2006.01.010 